\title{
A complex approach to a complex problem: the use of whole-genome sequencing in monitoring avian-pathogenic Escherichia coli - a review
}

\author{
Aneta Papouskova, Alois Cizek \\ University of Veterinary and Pharmaceutical Sciences Brno, Faculty of Veterinary Medicine, \\ Department of Infectious Diseases and Microbiology, Brno, Czech Republic
}

Received July 7, 2020

Accepted September 14, 2020

\begin{abstract}
Infections associated with Escherichia coli are responsible for immense losses in poultry production; moreover, poultry products may serve as a source of pathogenic and/or resistant strains for humans. As early as during the first hours of life, commercially hatched chickens are colonized with potentially pathogenic $E$. coli from the environment of hatcheries. The source of contamination has not been quite elucidated and the possibility of vertical spread of several avian pathogenic E. coli (APEC) lineages has been suggested, making the hatcheries an important node where cross-contamination of chicken of different origin can take place. The recent technological progress makes the method of whole-genome sequencing (WGS) widely accessible, allowing high-throughput analysis of a large amount of isolates. Whole-genome sequencing offers an opportunity to trace APEC and extended-spectrum/plasmid-encoded AmpC beta-lactamasesproducing E. coli (ESBL/pAmpC-E.coli) along the poultry processing chain and to recognize the potential pathways of "epidemic" sequence types. Data from WGS may be used in monitoring antimicrobial resistance, comparative pathogenomic studies describing new virulence traits and their role in pathogenesis and, above all, epidemiologic monitoring of clonal outbreaks and description of different transmission routes and their significance. This review attempts to outline the complexity of poultry-associated E. coli issues and the possibility to employ WGS in elucidating them.
\end{abstract}

Avian colibacillosis, sequence types, virulence plasmids, hatcheries, poultry production chain

Escherichia coli is an intriguing pathogen of poultry. It contributes to several distinct syndromes, commonly referred to as colibacillosis, a cause of non-negligible losses in poultry industry (Nolan et al. 2013). Different forms of colibacillosis affect all production categories; $E$. coli is the most common cause of increased first-week mortality in chicken due to yolk-sac-infection and septicaemia with or without omphalitis (Olsen et al. 2012; Poulsen et al. 2017), airsacculitis, polyserositis and septicaemia in broilers (Pourbakhsh et al. 1997) and salpingitis/peritonitis or acute septicaemia in layers (Vanderkerchove et al. 2004). Until recently, colibacillosis had been considered merely an opportunistic infection, secondary to several predisposing factors, such as viral and mycoplasmatal respiratory infections, high ammonium concentrations, environmental stress and immunosuppression (Oyetunde et al. 1978; Nakamura et al. 1992; 1994), although its association with several serogroups (O1, O2, O78) had been acknowledged (Sojka and Carnaghan 1961). However, progress in genotyping methods has revealed that strains implicated in poultry $E$. coli infections are distinct from common commensals, differing in possession of putative virulence-associated sequences (Rodriguez-Siek et al. 2005; Maturana et al. 2011) and presumably forming a specific pathotype - APEC (avian pathogenic E. coli). Nonetheless, this pathotype remains ill-defined. The inherent genomic plasticity, leading to the extreme diversity of colibacillosis-associated strains, as well as high prevalence and economic importance of colibacillosis make effective 
diagnosis, monitoring and intervention strategies both the more desirable and challenging. While useful rapid typing methods based on PCR-detection of selected virulenceassociated genes have been proposed (Ewers et al. 2005; Johnson et al. 2008; Schouler et al. 2012), our knowledge of the APEC virulence and its interaction with the host organism is still extremely deficient. It is clear that in order to understand such complex pathogens, more complex approaches must be employed.

\section{Difficulties with definition of APEC and the role of plasmids}

As avian colibacillosis comprises almost exclusively extraintestinal infections, APEC may be also considered a subgroup of ExPEC (extraintestinal pathogenic E. coli) along with well-established pathotypes NMEC (neonatal meningitis) and UPEC (uropathogenic) of humans and other mammals. In fact, they share enough genotypic and phenotypic features to raise concern about APEC's zoonotic potential. Human ExPEC as well as APEC strains typically carry a set of virulence-associated genes encoding for adhesins, siderophores, serum resistance etc., enabling them to invade and survive in the hostile environment of the host's system (Dho-Moulin and Fairbrother 1999; Johnson and Russo 2005). Some highly-conserved virulence-associated genes are encoded in the so called core genome, most of them, though, form a part of the accessory genome and are carried on mobile genetic elements, such as plasmids or genomic islands (Dobrindt 2005).

Virulence traits have been associated with ColV-type plasmids of the F incompatibility group. They are known to encode for colicin $\mathrm{V}$, which is not considered a virulence factor itself, and several iron-acquisition systems, complement resistance and other traits (Waters and Crosa 1991). In UPEC, prevalence of these plasmids is relatively low and several chromosomal pathogenicity-associated islands (PAIs) have been described, but they are very common in NMEC and namely APEC (Johnson et al. 2005; Johnson et al. 2006; Johnson et al. 2007; Johnson et al. 2010; Johnson et al. 2012); in fact, the presence of plasmid-associated virulence genes is so high that it has been suggested to be a defining feature of the APEC pathotype (Rodriguez-Siek et al. 2005). Johnson et al. (2006) described a virulence-associated conserved region of ColV plasmids and developed a PCR protocol detecting 5 of these genes (ompT, iutA, iroN, iss and $h l y F)$ as minimal predictors of APEC (Johnson et al. 2008).

Not only are ColV plasmids highly prevalent in APEC, they are also positively associated with its virulence and their presence can turn a non-pathogenic commensal strain into a pathogen, with enhanced virulence in both chicken and mammalian infection model (Skyberg et al. 2006). Co-transfer with resistance plasmids is also possible. However, this can be achieved only with a suitable recipient and a certain chromosomal background is required for these virulence plasmids to be maintained and/or expressed (Ginns et al. 2000). While human ExPEC mostly derive from phylogenetic groups B2 (Johnson and Russo 2005), the suitable core genome of APEC is more obscure; APEC are commonly found also in groups widely associated with commensals and intestinal pathotypes, such as A, B1 and C (Ewers et al. 2007; Cordoni et al. 2016). Moreover, although ColV-associated virulence region is recognized as a distinctive feature of APEC and its genes have been shown to contribute to virulence, its role in pathogenesis of particular colibacillosis syndromes has never been elucidated. Both NMEC and UPEC are usually more easily defined by determinants specific to the syndrome's pathogenesis (e.g. Ibe invasins mediating invasion of brain endothelium in NMEC) (Dale and Woodford 2015) - although this is always less clear than in intestinal pathotypes. Anyway, we know no set of genes that could be held responsible for specific pathogenesis of colibacillosis or its particular syndromes. Existence of distinct syndrome-specific subpathotypes has been proposed by Maturana et al. (2011). Is it possible that there are other genetic features, 
establishing different APEC subpathotypes, e.g. airsacculitis or salpingitis-associated? Or are they generalists, not quite as adapted as UPEC or NMEC to cause a specific disease, forming something we might call a quasi-pathotype?

Da Silveira et al. (2002) described low virulence in omphalitis-associated isolates from one-day-old chickens, stressing the opportunistic character of many E. coli infections in poultry. On the other hand, outbreaks caused by a highly virulent strain, supposedly acting as a primary pathogen, have been described (Zanella et al. 2000; Vanderkerchove et al. 2004). It is conceivable that different syndromes are more or less associated with opportunistic infections, which are caused by heterogenous, commensal-like strains, whereas for a certain portion "typical" APEC are responsible. The role of predisposing factors must always be taken into consideration while dealing with colibacillosisassociated outbreaks. This fact renders definition of APEC pathotype particularly difficult. Traditionally, an isolate obtained from an affected extraintestinal tissue from a bird showing typical clinical symptoms may be considered APEC; not always such isolates carry APECdefining features (virulence-associated genes). This may be explained by contamination of the sample, opportunistic character of that infection or presence of unrecognized virulenceassociated genes. However, these discrepancies have led to doubts whether the concept of the APEC pathotype can be justified (Collingwood et al. 2014).

\section{Sequence types and clonal lineages of APEC}

Among diverse ExPEC strains implicated in human hospital or community-acquired infections, several highly successful clonal lineages have been described, e.g. sequence types ST69, ST73, ST95, ST131, ST648 etc. These lineages are effective gut colonizers, easily transmitted between hosts, often linking high virulence with antimicrobial resistance; these characteristics render them fit to gain world-wide predominance over other ExPEC strains (Dale and Woodford 2015; Methers et al. 2015). Despite the overall diversity, evidence of the clonal character of some colibacillosis outbreaks has been given as early as in the 1980's (Whittam and Wilson 1988; White et al. 1993). Since then, several studies have confirmed the existence of predominant poultry-adapted sequence types, both outbreak-associated and asymptomatic gut colonizers (Ewers et al. 2009; Ronco et al. 2017; Pietsch et al. 2018). Interestingly, the phylogenetic origin and virulence genotype can be very diverse, although ColV-plasmid virulence-associated region is widely distributed; e.g. O78-H9-ST23 strains from phylogroup C are genetically closer to human intestinal-pathogenic strains, while others, like O1/O18/O45-ST95 from B2 phylogroup, represent potential zoonotic ExPEC. These findings again stress the diverse character of APEC and the importance of ColV plasmids; strains of a quite dissimilar phylogenetic origin have adapted to cause clinically the same disease in poultry (Dziva et al. 2013; Lemaître et al. 2013).

It is of a great public concern that many of these sequence types are overlapping between poultry and human-associated ExPEC (Maluta et al. 2014). Poultry has been suggested as a potential reservoir or even direct source of virulent human ExPEC (Mora et al. 2009; Mora et al. 2013; Cunha et al. 2017). Liu et al. (2018) described a presumably poultryadapted ST131-H22 sublineage, asymptomatically colonizing the guts of healthy broilers and carrying the ColV-type plasmid. As an asymptomatic intestinal colonization of a varying length precedes the development of an extraintestinal infection, it is challenging to prove the link between the outbreak strain and its original source. However, the frequent isolation of potentially zoonotic and/or multidrug-resistant strains from poultry and poultry products implies their epidemiologic importance (Manges 2016; Pietsch et al. 2018). Poultry products as a source of ESBL/AmpC-producing E. coli, which may also carry features typical of APEC, are being intensively studied; animals colonized with undesirable strains 
are considered their main reservoir and faecal bacteria are known to readily contaminate the carcasses at slaughterhouses (Drugdova and Kmet' 2013), however, secondary crosscontamination can also easily occur during the processing and manipulation with products (Bardon̆ et al. 2018).

Avian-pathogenic E. coli and human ExPEC may overlap, but they are not the same; it seems that we are dealing with two distinct, though related issues: ExPEC strains asymptomatically colonizing poultry, which may serve as a reservoir and source of human infection through contaminated poultry products; and clonal lineages of APEC that spread and cause outbreaks in poultry flocks of distinct regions, possibly worldwide. O25b:H4B2-ST131-H22 could represent the first group, whereas ST95 is a typical sequence type implicated both in avian and human disease (mostly bacteraemia and neonatal meningitis). Indeed, there is a subset of APEC within B2 phylogroup that are genetically indistinguishable from human ExPEC and are virulent both in avian and mammalian infection models (Moulin-Schouler et al. 2007; Tivendale et al. 2010; Zhu Ge et al. 2014). Cunha et al. (2017) reported a multidrug resistant high-risk O6-B2-ST73 clone causing outbreaks of colibacillosis in Brazil. ST73 had not been implicated in avian disease before. Another potentially zoonotic lineage, O78:H4-F-ST117, spreading between flocks in several Nordic countries, has been reported by Ronco et al. (2017). On the other hand, O2:H1-B2-ST429 and O78:H9-C-ST23 may represent specific poultry-adapted clonal lineages (Ewers et al. 2009; Sola-Ginés et al. 2015; Pietsch et al. 2018; Cummins et al. 2019).

\section{Are APEC vertically transmitted through the production pyramid?}

The chicken gut is the main reservoir of "potential APEC" (Ewers et al. 2009). Colonized chicken are the source of environmental contamination and horizontal transmission of pathogenic strains. Inhalation of contaminated dust is probably the most important route of infection, though contamination of an unhealed navel, skin scratches and ascendant infection of the oviduct are implicated mainly in localized forms of colibacillosis. Insufficient sanitation may permit persistence of certain strains in the environment of poultry houses and subsequent infection of flocks (Daehre et al. 2017). However, regarding the spread of widely distributed clonal lineages, possibility of their vertical transmission through the production chain must be considered.

Vertical transmissions of virulent APEC strains from parent flocks to broilers have been reported by Giovanardi et al. (2005). Moreover, Petersen et al. (2006) tracked a septicaemia-associated outbreak clone to the parent flock via the hatchery. The same pulsotypes were found in a parent flock, newly hatched chicks and in the subsequent broiler flock in association with first-week mortality by Poulsen et al. (2017). Breeders may be the source of bacterial strains for their progeny, either by a true vertical transmission from an infected ovary/oviduct, or by a "pseudovertical" spread, according to Projahn et al. (2017) referring to faecal contamination of eggs with occasional penetration of bacteria through the shell. Bacterial contamination is efficiently reduced by disinfection, but some bacteria may survive, possibly hidden in egg-shell pores, as suggested by Mezhoud et al. (2016), contaminating the environment of the hatchery and colonizing the gut of newly-hatched chicks. Additionally, E. coli infecting embrya in ovo may cause only negligible embryonic mortality; these chicks may hatch and serve as a source of $E$. coli strains for chicks from the same hatcher (Montgomery et al. 1999). Besides the oral route, inhalation of contaminated fluff is considered an effective means of transmission (Zhao et al. 2019).

Most studies investigating vertical transmission of $E$. coli and the role of hatcheries focus on ESBL/AmpC producing Enterobacteriaceae, as reviewed by Dame-Korevaar (2019). There is actually no compelling evidence that a true vertical transfer of these bacteria would play a significant role, although we may ask whether this also applies to APEC and 
whether salpingitis-associated strains indeed do not infect embrya, leading to increased first-week mortality. Instead, an occasional "pseudovertical" transfer is suggested as a main route of contamination of newly-hatched chicks, with hatcheries potentially serving as a bottleneck, allowing only transmission of the most efficiently colonizing and persistent strains (Projahn et al. 2018). Commercially hatched chicks deprived of a natural source of healthy microbiota are readily colonized with undesirable enterobacteria from the environment (Kubasova et al. 2019). If an important pathogenic lineage occurs among the bacteria surviving disinfection, it may multiply to considerable levels, irrespective of its source. One-day-old chicks are already colonized by ESBL/AmpC producing organisms and potential APEC and contaminate the environment of poultry-houses and vice-versa (Laube et al. 2013; Kemmett et al. 2014; Huibers et al. 2016). Longitudinal studies showed a decreasing diversity of colonizing strains during the fattening period and a shift in predominant STs (sequence types) (Kemmett et al. 2013; Van Hoek et al. 2018); the fattening or rearing period therefore may serve as another "bottleneck", selecting only the most successful colonizers. It is possible that from the original heterogenous population colonizing one-day-old chicks and associated with early mortalities (corresponding to the mostly opportunistic character of these infections as reported by da Silveira et al. [2002]) only certain clonal lineages are selected. The gut of young chicks provides a favourable environment for the horizontal transfer of resistance and/or virulence-associated plasmids and there may even exist a link between these two features, as stressed by Skyberg et al. (2006) and Johns on et al. (2010). However, more longitudinal studies monitoring the occurrence and transmission of APEC at each stationary step of the broiler production chain (sampling parent flocks, hatcheries and during the fattening/rearing period), as shown in Fig. 1, are needed to confirm these concepts.

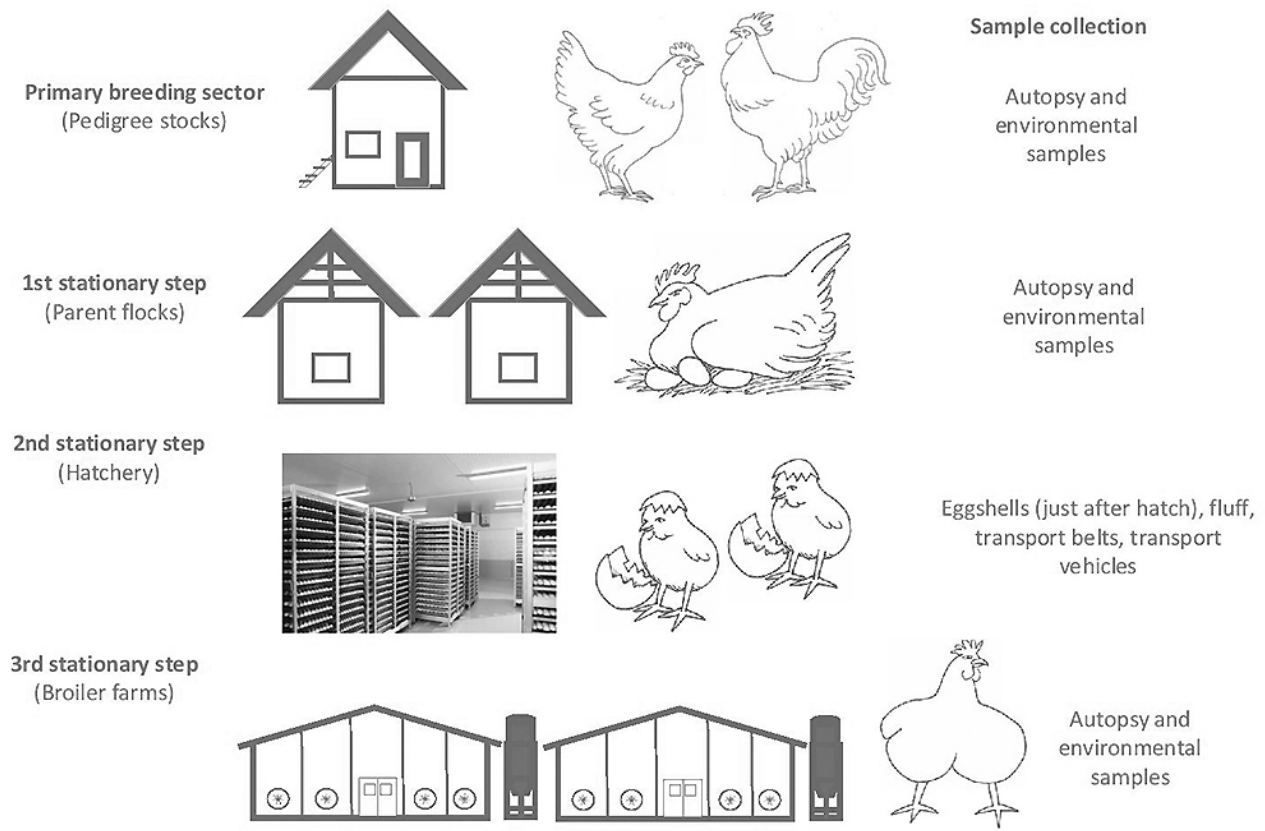

Fig. 1. Schematic view of the broiler production pyramid and sampling levels for APEC and/or ESBL/pAmpCEscherichia coli assessment

APEC - avian-pathogenic Escherichia coli; ESBL - extended-spectrum beta-lactamases; pAmpC - plasmidencoded AmpC beta-lactamases 


\section{The use of WGS in monitoring APEC occurrence}

The diagnosis of avian colibacillosis is traditionally based on the isolation of the bacterium from the affected extraintestinal tissues; bone marrow swabs are appropriate in cases of septicaemia. Care must be taken to avoid contamination by faecal microbiota. Serotyping has been ordinarily used for a basic characterization, although it is far from satisfactory; besides common APEC serogroups O1, O2 and O78, many APEC belong to "atypical" serogroups (e.g. O111) or are untypeable (Zanella et al. 2000; Zhao et al. 2005). Given the acknowledged link between the APEC status and presence of certain virulence-associated genes (many of them carried on plasmids), PCR genotyping proved far more informative and several already mentioned protocols have been proposed for a rapid prediction of the virulence potential of the isolates under study (Ewers et al. 2005; Johnson et al. 2008; Schouler et al. 2012). An experimental infection nevertheless remains the only definitive method of confirming their true virulence (Antão et al. 2008; Guabiraba and Schouler 2015).

For a further characterization, other methods like multilocus sequence typing (MLST) and pulse-field gel electrophoresis (PFGE) have been employed to study clonality and phylogenetic relationships between isolates from colibacillosis outbreaks, and to monitor the long-term prevalence of certain strains on the given territory (Ewers et al. 2009; Sola-Ginés et al. 2015). The PCR-based Clermont scheme (Clermont et al. 2013) of classification of isolates into 7 phylogenetic groups (A, B1, B2, C, D, E, F) is also widely used to provide information of their phylogenetic background. Furthermore, the antimicrobial susceptibility testing makes a standard component of a bacteriological examination and is extremely important given the increasing resistance to important antimicrobials in poultry-derived E. coli strains (Ibrahim et al. 2019).

However, all these methods have considerable limitations when it comes to the extreme diversity of the APEC population, related to the intrinsic plasticity of the E. coli genome. More advanced approaches are required if we are to understand the APEC virulence, transmission and population dynamics in their complexity and consequently, to devise efficient intervention strategies. It is actually this diversity that impedes the development of a widely applicable vaccine, although several APEC-associated surface proteins have been proposed as vaccine targets and Poulvac E. coli (Filho et al. 2013) is commonly used to protect layer flocks especially from the O78 serogroup (Sadeyen et al. 2015; Van Goor et al. 2017). In any case, the possibility to monitor the occurrence of virulent APEC/ExPEC strains and their transmission throughout the whole production chain is essential in order to detect the critical points of intervention to prevent outbreaks in production flocks and to prevent the contamination of poultry products, which seem to represent a potential source of infection for humans.

The next-generation sequencing is becoming more and more accessible for diagnostic laboratories (Lynch et al. 2016). It can be used for the whole-genome sequencing of new wild-type strains and their comparison to reference strains. The decreasing costs of and advances in computational technologies processing the enormous amount of generated data allow us to sequence great numbers of isolates and to compare them. The high-throughput sequencing facilitates the detection of resistance and virulence genes by searching the databases, as well as assigning the isolates to serotypes, sequence types, and phylogenetic groups. The core genome single-nucleotide polymorphisms analysis allows the construction of phylogenetic trees and assessment of the phylogenetic distance between isolates. Obviously, there are multiple impediments which may render data interpretation tricky. For example, using platforms generating short reads (like Illumina) makes it only possible to identify replicons, but not to analyse plasmids and other mobile elements in detail. Long-read sequencing platforms (e.g. Nanopore sequencing) is needed to assemble a complete plasmid sequence. However, these challenges will undoubtedly be overcome over time. 
The data produced by WGS can be employed in metagenomic studies monitoring antibiotic resistance in clinical and environmental samples, comparative pathogenomic studies describing new virulence traits and their function, virulence markers fit for use in diagnostic procedures and also potential vaccine targets. Moreover, as shown in Fig. 2 (Plate VIII), WGS is applicable in epidemiologic studies tracing outbreak-associated high-risk sequence types to reveal their transmission routes. Several studies have chosen this complex approach to assess the diversity of APEC isolates (Cordoni et al. 2016; Ronco et al. 2017; Cummins et al. 2019; Rafique et al. 2020; Poulsen et al. 2020; Papouskova et al. 2020). Others have focused on ESBL/AmpC producing E. coli and their spread through the production chain (Daehre et al. 2017; Projahn et al. 2018; Oikarainen et al. 2019) and their presence in poultry products (Pietsch et al. 2018). These studies have not revealed any distinct syndrome-associated subpathotypes, but have confirmed the prevalence of certain STs in poultry, namely ST23 (phylogroup C), ST95, ST354, ST429 (phylogroup B2) and ST117 (phylogroup F), and supported the assumption of possible vertical transmission through production pyramid to distant flocks, with hatcheries potentially representing a critical point where first cross-contamination occurs.

\section{Conclusion}

Up to now, research has revealed that APEC are not a single entity; the pathotype comprises strains with a varying degree of adaptation to different host and tissues. While some ST95 lineages of B2 phylogroup may form a mixed ExPEC pathotype, in which APEC and human ExPEC are indistinguishable, others may be more poultry-specific. Irrespective of their phylogeny, virulence-associated regions of ColV plasmids are widespread among APEC strains and seem to be of a vital importance for APEC virulence.

Several studies have suggested that specific clones can spread through the production chain from parent flocks to their progeny and consequently to poultry products, with hatcheries constituting an important intersection. This is of an extreme importance to both farmers and public, as poultry is considered a reservoir of resistant E. coli strains, and, at the same time, it may be a source of potentially zoonotic pathogens. A detailed, long-term regional monitoring of poultry farms, hatcheries and poultry products should be employed. However, the vague and inconsistent definition of APEC has so far impeded the interpretation of diverse and often contradictory data produced by different methods of study. The whole-genome sequencing is the most suitable approach and its application in extensive numbers of isolates have already provided interesting results, promising to shed a little more light on the issue of APEC pathogenicity and transmission.

\section{Acknowledgements}

This work was supported by the projects QK1810462 and 116/2016/FVL. The authors acknowledge the financial support from Internal Creative Agency of University of Veterinary and Pharmaceutical Sciences Brno, FVL/CELER/ITA2020.

\section{References}

Antão E-M, Glodde S, Li G, Sharifi R, Homeier T, Laturnus C, Diehl I, Bethe A, Philipp H-C, Preisinger R, Wieler LH, Ewers C 2008: The chicken as a natural model for extraintestinal infections caused by avian pathogenic Escherichia coli (APEC). Microb Pathogen 45: 361-369

Bardoň J, Mlynárčik P, Procházková P, Röderová M, Mezerová K, Kolář M 2018: Occurrence of bacteria with a dangerous extent of antibiotic resistance in poultry in the Central Region of Moravia. Acta Vet Brno 87: $165-172$

Clermont O, Christenson JK, Denamur E, Gordon DM 2013: The Clermont Escherichia coli phylo-typing method revisited: improvement of specificity and detection of new phylogroups. Environ Microbiol Rep 5: 58-65

Collingwood C, Kemmett K, Williams N, Wigley P 2014: Is the concept of avian pathogenic Escherichia coli as a single pathotype fundamentally flawed? Front Vet Sci 1: 1-4 
Cordoni G, Woodward MJ, Wu H, Alanazi M, Wallis T, La Ragione RM 2016: Comparative genomics of European avian pathogenic E. coli (APEC). BMC Genom 17: 960

Cummins ML, Reid CJ, Roy Chowdhury P, Bushell RN, Esbert N, Tivendale KA, Noormohammadi AH, Islam S, Marenda MS, Browning GF, Markham PF, Djordjevic SP 2019: Whole genome sequence analysis of Australian avian pathogenic Escherichia coli that carry the class 1 integrase gene. Microb Genom 5: e000250

Cunha MPV, Saidenberg AB, Moreno AM, Ferreira AJP, Vieira MAM, Gomes TAT, Knöbl T 2017: Pandemic extra-intestinal pathogenic Escherichia coli (ExPEC) clonal group O6-B2-ST73 as a cause of avian colibacillosis in Brazil. PLoS One: 12, e0178970-e0178970

da Silveira WD, Ferreira A, Brocchi M, Maria de Hollanda L, Pestana de Castro AF, Tatsumi Yamada A, Lancellotti M 2002: Biological characteristics and pathogenicity of avian Escherichia coli strains. Vet Microbiol 85: 47-53

Daehre K, Projahn M, Semmler T, Roesler U, Friese A 2017: Extended-spectrum beta-lactamase-/AmpC betalactamase-producing Enterobacteriaceae in broiler farms: transmission dynamics at farm level. Microb Drug Resist 24: $511-518$

Dale AP, Woodford N 2015: Extra-intestinal pathogenic Escherichia coli (ExPEC): Diseae, carriage and clones. J Infect 71: 615-626

Dame-Korevaar A, Fischet EAJ, van der Goot J, Stegeman A, Mevius D 2019: Transmission routes of ESBL/ pAmpC producing bacteria in the broiler production pyramid, a literature review. Prevent Vet Med 162: 136-150

Dho-Moulin M, Fairbrother JM 1999: Avian pathogenic Escherichia coli (APEC). BMC Vet Res 30: 299-316

Dobrindt U 2005: (Patho-)Genomics of Escherichia coli. Inter J Med Microbiol 295: 357-371

Drugdova Z, Kmet V 2013: Prevalence of $\beta$-lactam and fluoroquinolone resistance, and virulence factors in Escherichia coli isolated from chickens in Slovakia. Biologia 68: 11-17

Dziva F, Hauser H, Connor TR, van Diemen PM, Prescott G, Langridge GC, Eckert S, Chaudhuri RR, Ewers C, Mellata M, Mukhopadhyay S, Curtiss R 3rd, Dougan G, Wieler LH, Thomson NR, Pickard DJ, Stevens MP 2013: Sequencing and functional annotation of avian pathogenic Escherichia coli serogroup O78 strains reveal the evolution of $E$. coli lineages pathogenic for poultry via distinct mechanisms. Infect Immun 81: 838-849

Ewers C, Janßen T, Kießling S, Philipp HC, Wieler LH 2005: Rapid detection of virulence-associated genes in avian pathogenic Escherichia coli by multiplex polymerase chain reaction. Av Dis 49: 269-273

Ewers C, Li G, Wilking H, Kießling S, Alt K, Antáo E-M, Laturnus C, Diehl I, Glodde S, Homeier T, Böhnke U, Steinrück H, Philipp HC, Wieler LH 2007: Avian pathogenic, uropathogenic, and newborn meningitis-causing Escherichia coli: How closely related are they? Inter J Med Microbiol 297: 163-176

Ewers C, Antão EM, Diehl I, Philipp HC, Wieler LH 2009: Intestine and environment of the chicken as reservoirs for extraintestinal pathogenic Escherichia coli strains with zoonotic potential. Appl Environ Microbiol 75: 184-192

Filho TF, Fávaro C, Ingberman M, Beirao BCB, Inoue A, Gomes L, Caron LF 2013: Effect of spray Escherichia coli vaccine on the immunity of poultry. Av Dis 57: 671-675

Ginns CA, Benham ML, Adams LM, Whithear KG, Bettelheim KA, Crabb BS, Browning GF 2000: Colonization of the respiratory tract by a virulent strain of avian Escherichia coli requires carriage of a conjugative plasmid. Infect Immun 68: 1535-1541

Giovanardi D, Campagnari E, Ruffoni LS, Pesente P, Ortali G, Furlattini V 2005: Avian pathogenic Escherichia coli transmission from broiler breeders to their progeny in an integrated poultry production chain. Av Pathol 34: $313-318$

Guabiraba R, Schouler C 2015: Avian colibacillosis: still many black holes. FEMS Microbiol Lett 362

Huibers PM, Graat EA, van Hoek AH, Veenman C, de Jong MC, van Duijkeren E 2016: Transmission dynamics of extended-spectrum beta-lactamase-producing Escherichia coli in a broiler flock without antibiotic use. Prev Vet Med 131: 12-19

Ibrahim RA, Cryer TL, Lafi SQ, Basha EA, Good L, Tarazi YH 2019: Identification of Escherichia coli from broiler chickens in Jordan, their antimicrobial resistance, gene characterization and the associated risk factors. BMC Vet Res 15: 159

Johnson JR, Russo TA 2005: Molecular epidemiology of extraintestinal pathogenic (uro-pathogenic) Escherichia coli. Inter J Med Microbiol 295: 383-404

Johnson TJ, Siek KE, Johnson SJ, Nolan LK 2005: DNA Sequence and comparative genomics of pAPEC-O2-R, an avian pathogenic Escherichia coli transmissible R plasmid. Antimicrob Agents Chemother 49: 4681-4688

Johnson TJ, Siek KE, Johnson SJ, Nolan LK 2006: DNA sequence of a ColV plasmid and prevalence of selected plasmid-encoded virulence genes among avian Escherichia coli strains. J Bacteriol 188: 745-758

Johnson TJ, Kariyawasam S, Wannemuehler Y, Mangiamele P, Johnson SJ, Doetkott C, Skyberg JA, Lynne AM, Johnson JR, Nolan LK 2007: The genome sequence of avian pathogenic Escherichia coli strain O1:K1:H7 shares strong similarities with human extraintestinal pathogenic E. coli genomes. J Bacteriol 189: 3228-3236

Johnson TJ, Wannemuehler Y, Doetkott C, Johnson SJ, Rosenberger SC, Nolan LK 2008: Identification of minimal predictors of avian pathogenic Escherichia coli virulence for use as a rapid diagnostic tool. J Clin Microbiol 46: 3987-3996

Johnson TJ, Jordan D, Kariyawasam S, Stell AL, Bell NP, Wannemuehler YM, Alarcón CF, Li G, Tivendale KA, Logue CM, Nolan LK 2010: Sequence analysis and characterization of a transferable hybrid plasmid encoding multidrug resistance and enabling zoonotic potential for extraintestinal Escherichia coli. Infect Immun 78: $1931-1942$ 
Johnson TJ, Wannemuehler Y, Kariyawasam S, Johnson JR, Logue CM, Nolan LK 2012: Prevalence of avianpathogenic Escherichia coli strain O1 genomic islands among extraintestinal and commensal E. coli isolates. J Bacteriol 194: 2846-2853

Kemmett K, Humphrey T, Rushton S, Close A, Wigley P, Williams NJ 2013: A longitudinal study simultaneously exploring the carriage of APEC virulence associated genes and the molecular epidemiology of faecal and systemic E. coli in commercial broiler chickens. PLoS ONE 8: e67749

Kemmett K, Williams NJ, Chaloner G, Humphrey S, Wigley P, Humphrey T 2014: The contribution of systemic Escherichia coli infection to the early mortalities of commercial broiler chickens. Av Pathol 43: 37-42

Kubasova T, Kollarcikova M, Crhanova M, Karasova D, Cejkova D, Sebkova A, Matiasovicova J, Faldynova M, Pokorna A, Cizek A, Rychlik I 2019: Contact with adult hen affects development of caecal microbiota in newly hatched chicks. PLoS ONE 14: e0212446

Laube H, Friese A, von Salviati C, Guerra B, Kasbohrer A, Kreienbrock L, Roesler U 2013: Longitudinal monitoring of extended-spectrum-beta-lactamase/AmpC-producing Escherichia coli at German broiler chicken fattening farms. Appl Environ Microbiol 79: 4815-4820

Lemaître C, Mahjoub-Messai F, Dupont D, Caro V, Diancourt L, Bingen E, Bidet P, Bonacorsi S 2013: A conserved virulence plasmidic region contributes to the virulence of the multiresistant Escherichia coli meningitis strain S286 belonging to phylogenetic group C. PLoS ONE 8: e74423

Liu CM, Stegger M, Aziz M, Johnson TJ, Waits K, Nordstrom L, Gauld L, Weaver B, Rolland D, Statham S, Horwinski J, Sariya S, Davis GS, Sokurenko E, Keim P, Johnson JR, Price LB 2018: Escherichia coli ST131-H22 as a foodborne uropathogen. mBio 9: e00470-18

Lynch T, Petkau A, Knox N, Graham M, Van Domselaar G 2016: A primer on infectious disease bacterial genomics. Clin Microbiol Rev 29: 881-913

Maluta RP, Logue CM, Casas MRT, Meng T, Guastalli EAL, Rojas TCG, Montelli AC, Sadatsune T, de Carvalho Ramos M, Nolan LK, da Silveira WD 2014: Overlapped sequence types (STs) and serogroups of avian pathogenic (APEC) and human extra-intestinal pathogenic (ExPEC) Escherichia coli isolated in Brazil. PLoS ONE 9: e105016

Manges AR 2016: Escherichia coli and urinary tract infections: the role of poultry-meat. J Clin Microbiol Infect 22: $122-129$

Maturana VG, de Pace F, Carlos C, Mistretta Pires M, Amabile de Campos T, Nakazato G, Guedes Stheling E, Logue CM, Nolan LK, Dias da Silveira 2011: Subpathotypes of avian pathogenic Escherichia coli (APEC) exist as defined by their syndromes and virulence traits. Open Microbiol J 5: 55-64

Methers AJ, Peirano G, Pitout JDD 2015: The role of epidemic resistance plasmids and international high-risk clones in the spread of multidrug-resistant Enterobacteriaceae. Clin Microbiol Rev 28: 565-591

Mezhoud H, Chantziaras I, Iguer-Ouada M, Moula N, Garmyn A, Martel A, Touati A, Smet A, Haesebrouck F, Boyen F 2016: Presence of antimicrobial resistance in coliform bacteria from hatching broiler eggs with emphasis on ESBL/AmpC-producing bacteria. Av Pathol 45: 493-500

Montgomery RD, Boyle CR, Lenarduzzi TA, Jones, LS 1999: Consequences to chicks hatched from Escherichia coli inoculated embryos. Av Dis 43: 553-563

Mora A, López C, Dabhi G, Blanco M, Blanco JE, Alonso MP, Herrera A, Mamani R, Bonacorsi S, MoulinSchouleur M, Blanco J 2009: Extraintestinal pathogenic Escherichia coli O1:K1:H7/NM from human and avian origin: detection of clonal groups B2 ST95 and D ST59 with different host distribution. BMC Microbiol 9: 132

Mora A, Viso S, López, C, Alonso MP, García-Garrote F, Dabhi G, Mamani R, Herrera A, Marzoa J, Blanco M, Blanco JE, Moulin-Schouleur M, Schouler C, Blanco J 2013: Poultry as reservoir for extraintestinal pathogenic Escherichia coli O45:K1:H7-B2-ST95 in humans. Vet Microbiol 167: 506-512

Moulin-Schouleur M, Répérant M, Laurent S, Brée A, Mignon-Grasteau S, Germon P, Rasschaert D, Schouler C 2007: Extraintestinal pathogenic Escherichia coli strains of avian and human origin: link between phylogenetic relationships and common virulence patterns. J Clin Microbiol 45: 3366-3376

Nakamura K, Cook JKA, Frazier JA, Narita M 1992: Escherichia coli multiplication and lesions in the respiratory tract of chickens inoculated with infectious bronchitis virus and/or E. coli. Av Dis 36: 881-890

Nakamura K, Ueda H, Tanimura T, Noguchi K 1994: Effect of mixed live vaccine (Newcastle disease and infectious bronchitis) and Mycoplasma gallisepticum on the chicken respiratory tract and on Escherichia coli infection. J Compar Pathol 111: 33-42

Nolan LK, Barnes HJ, Vaillancourt JP, Abdul-Aziz T, Logue CM. Colibacillosis. In: Swayne DE, Glisson JR, et al. (Eds). Diseases of Poultry. Ames, Iowa, USA: John Wiley \& Sons, Inc., 2013: pp. 751-805

Oikarainen PE, Pohjola LK, Pietola ES, Heikinheimo A 2019: Direct vertical transmission of ESBL/pAmpCproducing Escherichia coli limited in poultry production pyramid. Vet Microbiol 231: 100-106

Olsen RH, Christensen H, Bisgaard M 2012: Comparative genomics of multiple plasmids from APEC associated with clonal outbreaks demonstrates major similarities and identifies several potential vaccine-targets. Vet Microbiol 158: 3-4

Oyetunde OO, Thomson RG, Carlson HC 1978: Aerosol exposure of ammonia, dust and Escherichia coli in broiler chickens. Canadian Vet J 19: 187-193

Papouskova A, Masarikova M, Valcek A, Senk D, Cejkova D, Jahodarova E, Cizek A 2020: Genomic analysis of Escherichia coli strains isolated from diseased chicken in the Czech Republic. BMC Vet Res 16: 189 
Petersen A, Christensen JP, Kuhnert P, Bisgaard M, Olsen JE 2006: Vertical transmission of a fluoroquinoloneresistant Escherichia coli within an integrated broiler operation. Vet Microbiol 116: 120-128

Pietsch M, Irrgang A, Roschanski N, Brenner MG, Hamprecht A, Rieber H, Käsbohrer A, Schwarz S, Rösler U, Kreienbrock L, Pfeifer Y, Fuchs S, Werner G, RESET Study Group 2018: Whole genome analyses of CMY-2producing Escherichia coli isolates from humans, animals and food in Germany. BMC Genom 19: 601

Poulsen LL, Thofner I, Bisgaard M, Christensen JP, Olsen RH, Christensen H 2017: Longitudinal study of transmission of Escherichia coli from broiler breeders to broilers. Vet Microbiol 207: 13-18

Poulsen LL, Kudirkiene E, Jorgensen SL, Djordjevic SP, Cummins ML, Christensen JP, Christensen H, Bisgaard M, Thofner I 2020: Whole genome sequence comparison of avian pathogenic Escherichia coli from acute and chronic salpingitis of egg laying hens. BMC Vet Res 16: 148

Pourbakhsh SA, Boulianne M, Martineau-Doizé B, Dozois CM, Desautels C, Fairbrother JM 1997: Dynamics of Escherichia coli infection in experimentally inoculated chickens. Av Dis 41: 221-233

Projahn M, Daehre K, Roesler U, Friese A 2017: Extended-spectrum-beta-lactamase- and plasmid-encoded cephamycinase-producing enterobacteria in the broiler hatchery as a potential mode of pseudo-vertical transmission. J Appl Environ Microbiol 83: e02364-16

Projahn M, Daehre K, Semmler T, Guenther S, Roesler U, Friese A 2018: Environmental adaptation and vertical dissemination of ESBL-/pAmpC-producing Escherichia coli in an integrated broiler production chain in the absence of an antibiotic treatment. Microb Biotechnol 11: 1017-1026

Rafique M, Potter RF, Ferreiro A, Wallace MA, Rahim A, Ali Malik A, Siddique N, Abbas MA, D’Souza AW, Burnham C-AD, Ali N, Dantas G 2020: Genomic characterization of antibiotic resistant Escherichia coli isolated from domestic chickens in Pakistan. Front Microbiol 10: 3052

Rodriguez-Siek KE, Giddings CW, Doetkott C, Johnson TJ, Nolan LK 2005: Characterizing the APEC pathotype. Vet Res 36: 241-256

Ronco T, Stegger M, Olsen RH, Sekse C, Nordstoga AB, Pohjanvirta T, Lilje B, Lyhs U, Andersen PS, Pedersen K 2017: Spread of avian pathogenic Escherichia coli ST117 O78:H4 in Nordic broiler production. BMC Genomics 18: 13

Sadeyen J, Wu Z, Davies H, van Diemen PM, Milicic A, La Ragione RM, Kaiser P, Stevens MP, Dziva F 2015: Immune responses associated with homologous protection conferred by commercial vaccines for control of avian pathogenic Escherichia coli in turkeys. Vet Res 46: 5

Schouler C, Schaeffer B, Brée A, Mora A, Dahbi G, Biet F, Oswald E, Mainil J, Blanco J, Moulin-Schouleur M 2012: Diagnostic strategy for identifying avian pathogenic Escherichia coli based on four patterns of virulence genes. J Clin Microbiol 50: 1673-1678

Skyberg JA, Johnson TJ, Johnson JR, Clabots C, Logue CM, Nolan LK 2006: Acquisition of avian pathogenic Escherichia coli plasmids by a commensal $E$. coli isolate enhances its abilities to kill chicken embryos, grow in human urine, and colonize the murine kidney. Infect Immun 74: 6287-6292

Sojka WJ, Carnaghan RBA 1961: Escherichia coli infections in poultry. Res Vet Sci 2: 340-352

Solà-Ginés M, Cameron-Veas K, Badiola I, Dolz R, Majó N, Dahbi G, Viso S, Mora A, Blanco J, Piedra-Carrasco N, González-López JJ, Migura-Garcia L 2015: Diversity of multi-drug resistant avian pathogenic Escherichia coli (APEC) causing outbreaks of colibacillosis in broilers during 2012 in Spain. PLoS ONE 10: e0143191

Tivendale KA, Logue CM, Kariyawasam S, Jordan D, Hussein A, Li G, Wannemuehler Y, Nolan LK 2010: Avian-pathogenic Escherichia coli strains are similar to neonatal meningitis E. coli strains and are able to cause meningitis in the rat model of human disease. Infect Immun 78: 3412-3419

van Goor A, Stromberg ZR, Mellata M 2017: A recombinant multi-antigen vaccine with broad protection potential against avian pathogenic Escherichia coli. PLoS ONE 12: e0183929

van Hoek AHAM, Veenman C, Florijn A, Huijbers PMC, Graat EAM, de Greeff S, Dierikx CM and van Duijkeren E 2018: Longitudinal study of ESBL Escherichia coli carriage on an organic broiler farm. J Antimicrob Chemother 73: 3298-3304

Vandekerchove D, De Herdt P, Laevens H, Pasmans F 2004: Colibacillosis in caged layer hens: characteristics of the disease and the aetiological agent. Av Pathol 33: 117-125

Waters VL, Crosa JH 1991: Colicin V virulence plasmids. Microbiol Rev 55: 437-450

White DG, Dho-Moulin M, Wilson RA, Whittam TS 1993: Clonal relationships and variation in virulence among Escherichia coli strains of avian origin. Microb Pathogen 14: 399-409

Whittam TS, Wilson RA 1988: Genetic relationships among pathogenic strains of avian Escherichia coli. Infect Immun 56: 2458-2466

Zanella A, Alborali GL, Bardotti M, Candotti P, Guadagnini PF, Anna Martino P, Stonfer M 2000: Severe Escherichia coli $\mathrm{O} 111$ septicaemia and polyserositis in hens at the start of lay. Av Pathol 29: 311-317

Zhao S, Maurer JJ, Hubert S, De Villena JF, McDermott PF, Meng J, Ayers S, English L, White DG 2005: Antimicrobial susceptibility and molecular characterization of avian pathogenic Escherichia coli isolates. Vet Microbiol 107: 215-224

Zhao S, Wang C, Chang S, Tsai Y, Chou C 2019: Characterization of Escherichia coli isolated from day-old chicken fluff in Taiwanese hatcheries. Av Dis 63: 9-16

Zhu Ge X, Jiang J, Pan Z, Hu L, Wang S, Wang H, Leung FC, Dai J, Fan H 2014: Comparative genomic analysis shows that avian pathogenic Escherichia coli isolate IMT5155 (O2:K1:H5; ST complex 95, ST140) shares close relationship with ST95 APEC O1:K1 and human ExPEC O18:K1 strains. PLoS ONE 9: e112048 
Plate VIII

Papouskova A. et al.: A complex ... pp. 273-282

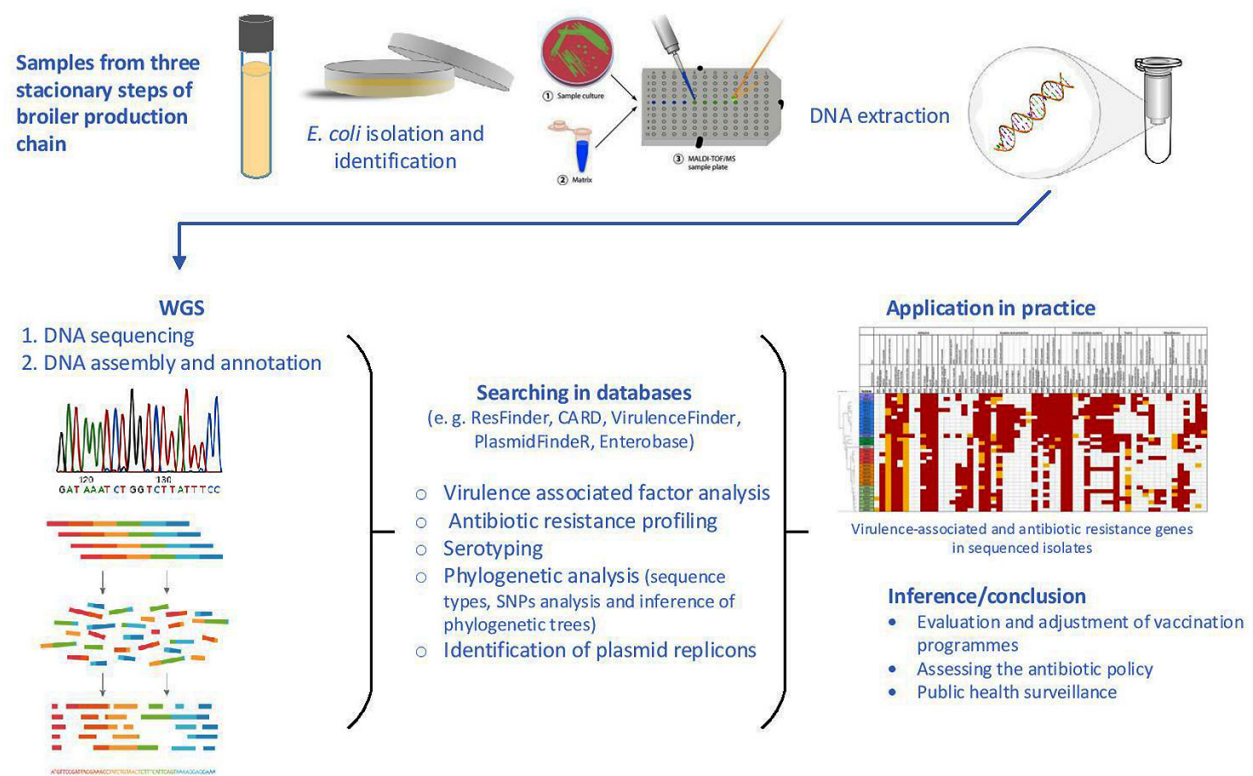

Fig. 2. Schematic workflow of WGS application in APEC and/or ESBL/pAmpC-Escherichia coli assessment

APEC - avian-pathogenic Escherichia coli; CARD - comprehensive antibiotic resistance database; ESBL - extended-spectrum beta-lactamases; pAmpC - plasmid-encoded AmpC beta-lactamases; WGS - wholegenome sequencing 